\title{
University Governance: Autonomy, Structures and Inclusiveness
}

\author{
Enora Bennetot Pruvot and Thomas Estermann
}

\section{Introduction}

The present article draws from the data collected in the framework of the 2017 update of the EUA University Autonomy Scorecard. ${ }^{1}$ The Scorecard was first launched in 2011 and offers an institutional perspective on university autonomy in Europe. It allowed for the development of a core set of indicators and a methodology to collect, compare and weight data on the topic. In this context, the regulatory frameworks of 29 higher education systems were analysed in order to assess the degree of autonomy universities operate with. The Scorecard is characterised by a four-pillar structure which allows to concretely assess university autonomy with regard to:

- organisational matters (covering academic and administrative structures, leadership and governance);

- financial matters (covering the ability to raise funds, own buildings, borrow money and set tuition fees);

\footnotetext{
The authors wish to thank Adisa Ejubovic for her work in compiling the data necessary for this paper.

${ }^{1}$ EUA's Autonomy Scorecard is composed of a report, published in 2017 (Pruvot and Estermann (2017) University Autonomy in Europe III: The Scorecard 2017. EUA, Brussels), as well as a compendium "University Autonomy in Europe III: Country Profiles" and an online tool available at www.university-autonomy.eu.
}

E. Bennetot Pruvot $(\bowtie) \cdot T$. Estermann

European University Association, Brussels, Belgium

e-mail: Enora.pruvot@eua.eu

T. Estermann

e-mail: thomas.estermann@eua.eu

(C) The Author(s) 2018

A. Curaj et al. (eds.), European Higher Education Area: The Impact of Past and Future Policies, https://doi.org/10.1007/978-3-319-77407-7_37 
- staffing matters (including the ability to recruit independently, promote and develop academic and non-academic staff);

- academic matters (including study fields, student numbers, student selection as well as the structure and content of degrees).

\section{Methodology and Data Collection}

The data collection was organised following the original Scorecard methodology, based on questionnaires and interviews, as well as several rounds of validation with national rectors' conferences, during which information was clarified and contextualised. The questionnaires submitted to the National Rectors' Conferences included the responses they gave in 2010 to enhance comparability over time. The questions address the capacity of universities to act on a series of topics, on the basis of the provisions of the relevant regulatory framework. Additional information was collected on the precise composition of university governing bodies. The data validation phase spanned over a year, from late 2015 to late 2016 , due to the need to correctly interpret responses to indicators but also understand the broader narrative for each system.

The publication in June 2017 of the updated Scorecard (Pruvot and Estermann 2017) included the new scoring and ranking of systems for each of the four dimensions described above as well as an overview of the related trends and recent developments. Nevertheless, the qualitative data collected in this context allowed for further exploitation. The present paper aims at mobilising this data with the view to generate a more in-depth picture of university governance models in Europe. Additional analysis was therefore carried out on data pertaining to "dimension 1" of the Autonomy Scorecard (organisational autonomy). Further data processing was performed, leading to a refined geographical scope including only those higher education systems for which relevant information was available. ${ }^{2}$ The present paper, therefore, encompasses 22 higher education systems, as listed below. Reference is made to other systems analysed under the Scorecard when data is available, with the aim to provide a more comprehensive picture (Tables 1 and 2).

\section{Scope of Analysis}

The table below summarises items pertaining to "organisational autonomy" surveyed and presented in the report "University Autonomy in Europe III:

\footnotetext{
${ }^{2}$ The higher education systems included in this analysis provided detailed information regarding the university governing bodies. This data was not available for all systems surveyed in the Autonomy Scorecard, as the methodology included specific features only.
} 
Table 1 Higher education systems included in the analysis

\begin{tabular}{|c|c|c|c|c|c|}
\hline Code & Country/system & Note & Code & $\begin{array}{l}\text { Country/ } \\
\text { system }\end{array}$ & Note \\
\hline AT & Austria & & IT & Italy & \\
\hline BE-FL & $\begin{array}{l}\text { Flanders } \\
\text { (Belgium) }\end{array}$ & Included in 2011 & LU & Luxembourg & \\
\hline $\mathrm{CZ}$ & Czech Republic & $\begin{array}{l}\text { Analysis carried } \\
\text { out after release } \\
\text { of } 2017 \text { update }\end{array}$ & NL & $\begin{array}{l}\text { The } \\
\text { Netherlands }\end{array}$ & \\
\hline $\begin{array}{l}\text { NRW } \\
\text { (DE) }\end{array}$ & $\begin{array}{l}\text { North } \\
\text { Rhine-Westphalia } \\
\text { (Germany) }\end{array}$ & & NO & Norway & \\
\hline DK & Denmark & & PL & Poland & \\
\hline EE & Estonia & & PT & Portugal & \\
\hline FI & Finland & & RS & Serbia & $\begin{array}{l}\text { Newly } \\
\text { included in } \\
\text { the update }\end{array}$ \\
\hline $\mathrm{HR}$ & Croatia & $\begin{array}{l}\text { Newly included } \\
\text { in the update }\end{array}$ & SE & Sweden & \\
\hline $\mathrm{HU}$ & Hungary & & SI & Slovenia & $\begin{array}{l}\text { Newly } \\
\text { included in } \\
\text { the update }\end{array}$ \\
\hline IE & Ireland & & SK & Slovakia & \\
\hline IS & Iceland & & UK & $\begin{array}{l}\text { United } \\
\text { Kingdom }\end{array}$ & $\begin{array}{l}\text { (England } \\
\text { only unless } \\
\text { otherwise } \\
\text { stated) }\end{array}$ \\
\hline
\end{tabular}

The Scorecard 2017" (Pruvot and Estermann 2017) and new data researched in this paper. All data were collected in the framework of the Autonomy Scorecard update but only specific elements were used for the Scorecard (second column). Additional data collected on the composition of governing bodies, their size, the types of external members included, etc., while collected at the same time, was not used for the Scorecard since it did not correspond to the methodology and is instead used for the present analysis (Table 3).

The comparative data presented in this paper is analysed under the lens of institutional autonomy. Few higher education systems allow universities to freely decide on their governance model. The types of bodies, their responsibilities, size and membership may be subject to different degrees of regulation. In exploring these elements, the focus is placed on the links between governance models, representation and inclusiveness in governing bodies and university organisational autonomy. 


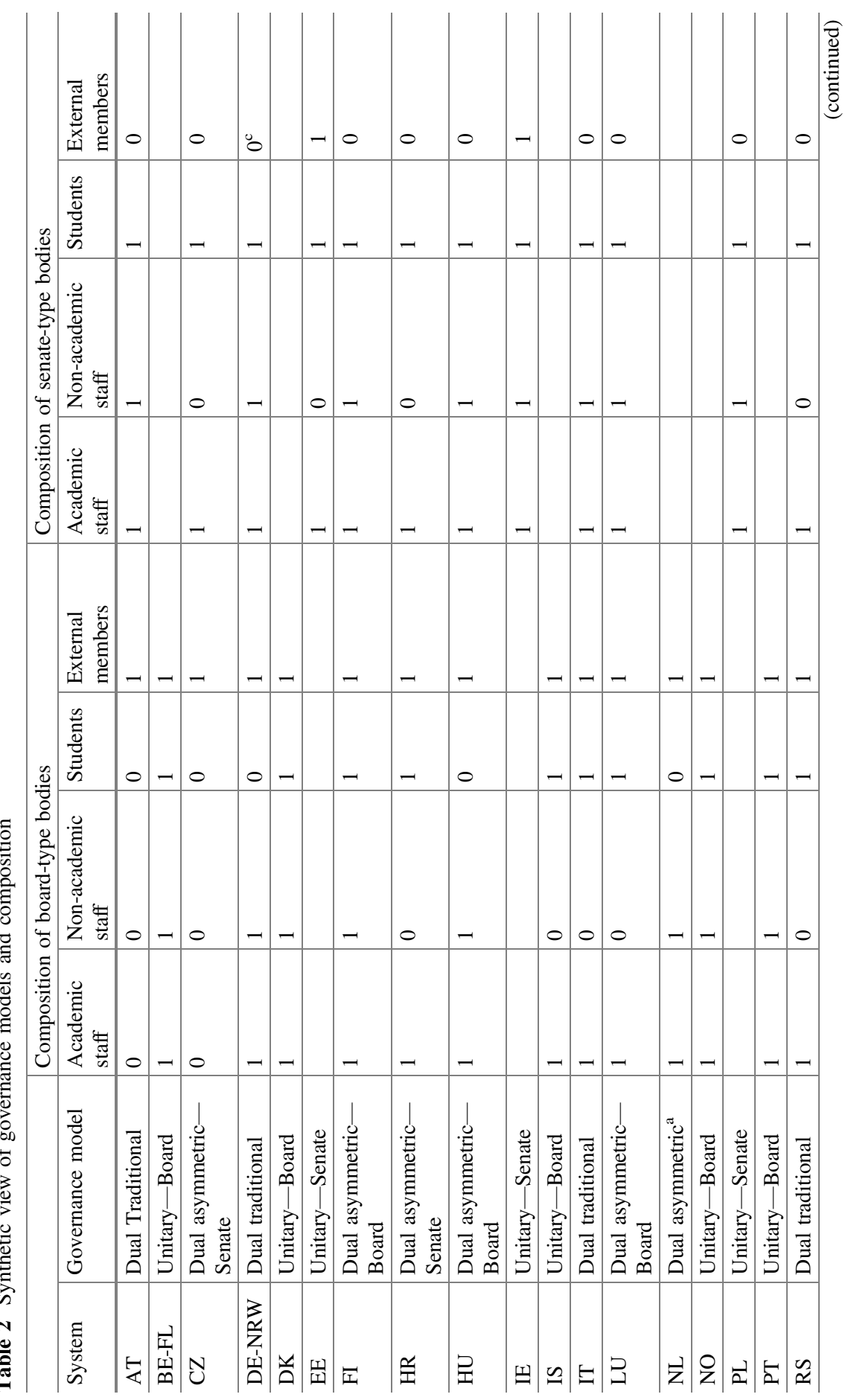




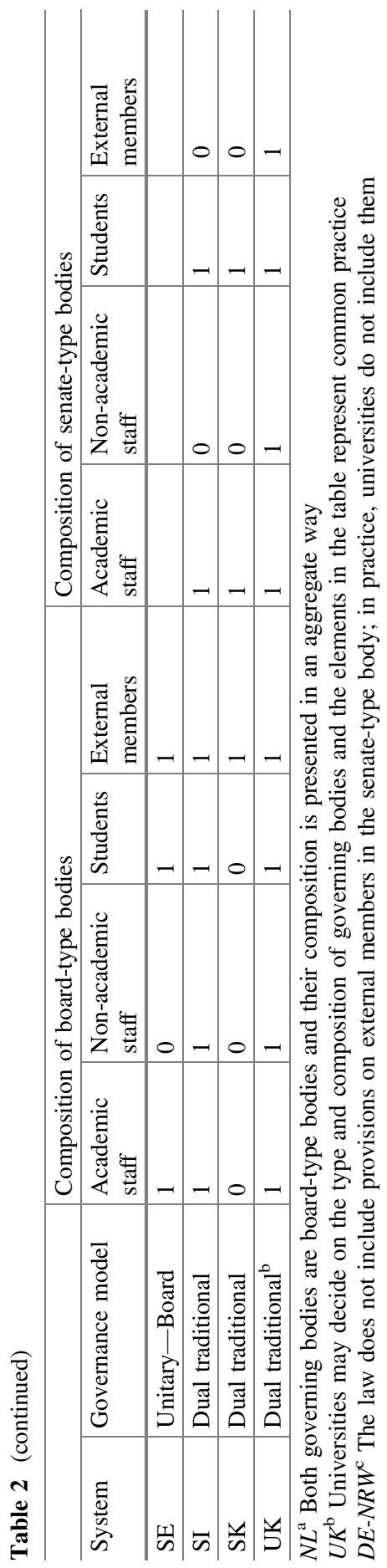




\section{Governance Models}

While significant diversity in the specifics of governance modalities exists across universities in Europe, general observations can be made about the types of internal bodies governing university activities. When comparing the information collected in the characteristics of these bodies as stated in law (holding formal decision-making powers), the distribution of responsibilities and the dynamics between them (in the cases where there is no single governing structure), it is possible to establish a typology of governance models and thus cluster higher education systems accordingly. Our analysis, therefore, distinguishes:

- Unitary governance models and

- Dual governance models

With the latter sub-divided based on power distribution, between:

- "traditional" model

- "asymmetric" model

The following sections explore this typology in further detail.

\section{Unitary Model}

"Unitary model" refers to the governing structures where one governing body exerts decision-making powers at the given university. This body can have the characteristics of either "senate-type" bodies or "board-type" bodies.

Senate and Board-type bodies are defined in relation to each other. Senate-type bodies tend to be primarily competent for academic matters and are characterised by their comparatively larger size and academic-oriented membership. Board-type bodies are usually responsible for strategic institutional decisions, often including financial aspects, and are often of smaller size than senate-type bodies. They are also characterised by a more diverse membership.

In the sample analysed, a minority of higher education systems use unitary governance models. Among them, the unitary models structured around board-type bodies are more frequent (six out of nine). Universities in Estonia, Ireland and Poland use senate-type bodies as the only decision-making structure. It should be noted that several regulatory frameworks exist in Estonia; in addition to the main Act governing activities of four universities, two universities are governed via specific laws that have introduced board-type bodies next to the existing senates, creating dual governance structures.

The composition of governing bodies in Ireland has been a bone of contention, with the university sector having expressed the wish to move away from traditionally large, group representation-based bodies. The argument is that the current regulations do not enable universities to select the right expertise at strategic level. The sector has therefore been advocating for steps in that direction, similar to the changes implemented in the regulatory framework for the Irish Institutes of 
Table 3 Scope of analysis

\begin{tabular}{|c|c|c|}
\hline Topic & 2017 Autonomy scorecard & Present analysis \\
\hline \multirow[t]{5}{*}{ Executive leadership } & Selection procedure & \\
\hline & Appointment & \\
\hline & Selection criteria & \\
\hline & Term of office & \\
\hline & Dismissal procedure & \\
\hline $\begin{array}{l}\text { Internal academic } \\
\text { structures }\end{array}$ & $\begin{array}{l}\text { Capacity to determine internal } \\
\text { academic structures }\end{array}$ & \\
\hline $\begin{array}{l}\text { Separate legal } \\
\text { entities }\end{array}$ & $\begin{array}{l}\text { Capacity to create independent legal } \\
\text { entities }\end{array}$ & \\
\hline \multirow[t]{5}{*}{ Governing bodies } & Types of governance structures & $\begin{array}{l}\text { Composition of } \\
\text { governing bodies }\end{array}$ \\
\hline & & $\begin{array}{l}\text { (Internal) members' } \\
\text { voting rights }\end{array}$ \\
\hline & & Size of governing bodies \\
\hline & Inclusion of external members & \\
\hline & Selection of external members & $\begin{array}{l}\text { External members' } \\
\text { profiles }\end{array}$ \\
\hline
\end{tabular}

Technology. Finally, Polish university senates stand out as comparatively "closed" governing bodies. They do not include external members who therefore are not represented at all in the university governance, an exception in Europe. Nevertheless, Polish universities have the latitude to establish and decide on the membership of additional advisory bodies.

The other unitary models concentrate decision-making powers in a board-type body. This does not preclude "advisory" bodies that tend to display complementary features to the decision-making body, such as wider academic staff or student representation. In particular, Denmark, Iceland and Portugal make it compulsory for universities to have a "senate" although this body does not possess effective decision-making powers.

With the exception of Finland, all Nordic systems have unitary governance models structured around board-type bodies. It is worth noting though that, in Sweden, some of the historically established universities maintain a senate-type body in addition.

\section{Dual Model}

"Dual models" are characterised by governance structures including both a senate-type body and a board-type body that share decision-making powers. This particular model is more frequently found across Europe (roughly $2 / 3$ of the systems analysed). Based on the distribution of power among the two bodies, two types of dual model can be distinguished. Both types are almost equally present. 


\section{Dual Traditional Model}

The "dual traditional" model is based on power division where generally each body has a distinct, but equally important portfolio of responsibilities; the senate-type body is usually in charge of academic affairs while the board-type body is generally tasked with strategic oversight and budget allocation. Both bodies may, nevertheless, also partake in the decision-making process on the same issues. Systems following this particular model include Austria, ${ }^{3}$ North Rhine-Westphalia, Italy, the UK, Serbia, Slovakia and Slovenia.

\section{Dual Asymmetric Model}

"Dual asymmetric" models comprise senate-type and board-type bodies, but with a different type of power dynamics leading to one body occupying a distinctly more central position in the decision-making process. The model can be found in the Czech Republic, Croatia, Finland, Hungary, Netherlands and Luxembourg. Board-type bodies tend to dominate in this model, while senates are the foci of power in exceptional cases. This model is distinct from unitary governance structures where the governing body may be "assisted" by advisory bodies which do not have formal decision-making capacities.

In France, university governance structures evolved from a unitary model to a dual asymmetric model with the implementation of a new Act passed in 2013, which modified the distribution of competencies among the governing bodies. Under the 2007 regulatory framework, the board combined strategic, management and HR competencies. It was complemented by two bodies of a more consultative nature, the "scientific council" and the "council for academic and student matters". The 2013 law implemented a change of competencies by focusing the board's activities on strategic matters and reshaping the two other bodies into two committees (one for research and one for teaching) that together form the "academic council". This senate-type body now acquired a series of competencies including a focus on staffing matters.

It can be observed that two-thirds of the sample (15 systems) have power localised either in one body (unitary model) only or in one body (either Senate or the Board) while the second entity has a more marginal/limited scope for decision-making (dual asymmetric model) (Table 4). Furthermore, board-type bodies are twice more frequently in a unique or central decision-making capacity than senate-type bodies. There is thus a significant degree of concentration of decision-making capacities in universities across Europe. The next section explores

\footnotetext{
${ }^{3}$ A specificity of Austria is that the law defines the rectorate as a collegial governing body on an equal footing with the board/council- and senate-type bodies.
} 
Table 4 University governance structures ${ }^{4}$

\begin{tabular}{l|l|l}
\hline Governing bodies & \multicolumn{1}{l}{} \\
\hline System & Senate-type & Board-type \\
\hline AT & $\checkmark$ & $\checkmark$ \\
\hline BE-FL & $\times$ & $\checkmark$ \\
\hline CZ & $\checkmark$ & $\checkmark$ \\
\hline DE-NRW & $\checkmark$ & $\checkmark$ \\
\hline DK & $\times$ & $\checkmark$ \\
\hline EE & $\checkmark$ & $\times$ \\
\hline FI & $\checkmark$ & $\checkmark$ \\
\hline HR & $\checkmark$ & $\checkmark$ \\
\hline HU & $\checkmark$ & $\checkmark$ \\
\hline IE & $\checkmark$ & $\times$ \\
\hline IS & $\times$ & $\checkmark$ \\
\hline IT & $\checkmark$ & $\checkmark$ \\
\hline LU & $\checkmark$ & $\checkmark$ \\
\hline NL & $\times$ & $\checkmark \checkmark$ \\
\hline NO & $\times$ & $\checkmark$ \\
\hline PL & $\times$ & $\times$ \\
\hline PT & $\checkmark$ & $\checkmark$ \\
\hline RS & $\times$ & $\checkmark$ \\
\hline SE & $\checkmark$ & $\checkmark$ \\
\hline SI & $\times$ & $\checkmark$ \\
\hline SK & $\checkmark$ & $\checkmark$ \\
\hline UK & $\checkmark$ & $\checkmark$ \\
\hline I Duth & $\checkmark$ & \\
\hline
\end{tabular}

${ }^{\mathrm{a}}$ The Dutch model is dual but presents unique characteristics, insofar as is it is composed of two board-type bodies ${ }^{\mathrm{b}}$ Universities in England, Wales and Northern Ireland can decide on their governance structures freely. Governance models and the operation of governing bodies of universities are guided by the "Higher Education Code of Governance" produced by the Committee of University Chairs. Universities typically have a dual governance structure, with a board/council-type body responsible for all strategic institutional matters and a senate-type body responsible for academic governance

the composition of governing bodies, allowing to assess whether the phenomenon described above has an impact on representativeness and inclusiveness of university governance structures, account taken of the role of regulation and intervention of public authorities in these matters.

\footnotetext{
${ }^{4}$ The tick marks in bold indicate the "central" governing body in dual asymmetric governance structures.
} 


\section{Composition of Governing Bodies}

\section{Size Regulation}

The capacity of universities to populate strategically their governing bodies may be limited in different ways, which can be cumulative: the type of governing body/ bodies may be prescribed - still a common feature in most higher education systems of Europe; regulation may apply to the size of the body/bodies; and regulations may apply to the composition of governing bodies.

With regard to the size of the governing bodies, the intervention modalities of public authorities may be of three types:

- "no regulation": universities are free to decide on the size of their governing bodies;

- "moderate regulation": public authorities specify either a minimum and/or maximum number of numbers in one or both governing bodies; or stipulate ratios between given groups to be represented in the governing bodies;

- "full regulation": public authorities specify the exact number of members pertaining to the university governing body.

Where universities may freely decide on the size of their governing bodies, as in England or in North Rhine-Westphalia (for the senate-type body), they generally reflect the size of the institution itself. The systems characterised by "moderate regulation" include systems where the ratio between certain member types is specified and systems that have maximum and/or minimum size provisions. Ratios typically apply to academic staff and/or student representatives. Furthermore, some systems have provisions in terms of minimum and maximum thresholds of certain member types. This includes Poland where it is specified that there should be 50 $60 \%$ of academic staff and minimum $20 \%$ of students. Certain systems have a minimum and/or maximum size of the senate-type body specified in the law. Minimum size is stipulated in Slovakia (min. 15 members), whereas maximum size is particularised in Italy (max. 35 members). Ireland has both minimum (20 members) and maximum (40 members) limits specified in the law. Last, some European systems regulate the size of senate-type bodies tightly by specifying the exact number of each member type. This is notably the case in Luxembourg (29 members), Austria (18 or 26 members), and Hungary (9 members). In the sample, the size of senate-type bodies is subject equally often to "full" or "moderate" regulation (Table 5).

On average composed of about 30 members (in the sample, where regulation on size exists), the senate-type bodies nevertheless show diverse characteristics across Europe. The smallest senate-type body can be observed in Hungary with 9 members. In terms of the upper threshold, one of the largest senate-type bodies is present in Estonia and Ireland with 40 members each. Although not included in the present analysis, Spain is an extreme case with universities allowed to have up to 300 members in their senates. Diversity also characterises the Swiss system, where university senates (that have mostly consultative competencies) range from 25 to around 200 members. Advisory bodies that resemble "senate-type bodies", but 
Table 5 Size regulation of university governing bodies

\begin{tabular}{|c|c|c|c|c|c|c|}
\hline \multicolumn{7}{|c|}{ Size regulation in governing bodies } \\
\hline \multirow[t]{2}{*}{ System } & \multicolumn{2}{|c|}{ Full regulation } & \multicolumn{2}{|c|}{$\begin{array}{l}\text { Moderate } \\
\text { regulation }\end{array}$} & \multicolumn{2}{|c|}{ No regulation } \\
\hline & Senate & Board & Senate & Board & Senate & Board \\
\hline AT & $\checkmark$ & & & $\checkmark$ & & \\
\hline BE-FL & & & & $\checkmark$ & & \\
\hline $\mathrm{CZ}$ & $\checkmark$ & $\checkmark$ & & & & \\
\hline DE-NRW & & & & $\checkmark$ & $\checkmark$ & \\
\hline DK & & & & $\checkmark$ & & \\
\hline $\mathrm{EE}$ & $\checkmark$ & & & & & \\
\hline FI & & & $\checkmark$ & $\checkmark$ & & \\
\hline HR & & & $\checkmark$ & $\checkmark$ & & \\
\hline HU & $\checkmark$ & $\checkmark$ & & & & \\
\hline IE & $\checkmark$ & & & & & \\
\hline IS & & $\checkmark$ & & & & \\
\hline IT & & & $\checkmark$ & $\checkmark$ & & \\
\hline $\mathrm{LU}$ & $\checkmark$ & $\checkmark$ & & & & \\
\hline NL & & $\checkmark \checkmark$ & & & & \\
\hline NO & & $\checkmark$ & & & & \\
\hline PL & & & $\checkmark$ & & & \\
\hline $\mathrm{PT}$ & & & & $\checkmark$ & & \\
\hline RS & & & $\checkmark$ & $\checkmark$ & & \\
\hline SE & & $\checkmark$ & & & & \\
\hline SI & & $\checkmark$ & $\checkmark$ & & & \\
\hline SK & & $\checkmark$ & $\checkmark$ & & & \\
\hline UK & & & & & $\checkmark$ & $\checkmark$ \\
\hline
\end{tabular}

without decision-making power, include considerably more members than the average senate, as is the case in Iceland where there are 90 members in that advisory body. State regulation therefore tends to limit the size of the governing bodies to enhance effective decision-making processes.

University board-type bodies are almost equally often subject to "full" and "moderate" regulation when considering size: either the exact number is specified or both lower and upper limits are imposed. Systems that allow universities to decide freely on the size of their board-type bodies remain the exception. As in England, Flemish universities can decide on the size, with the caveat that there must be $1 / 3$ of external members.

Among those systems that regulate the size of the board-type body, Netherlands has the smallest, with 3-5 members. At the other end, Portuguese universities may have up to 35 board members (with Spain, in par with its large senates, allowing up to 50 members in the board-type body). However, in most cases, the board-type bodies are on average comprised of around 10 members. The governance model must be considered: in unitary structures, the board-type body will tend to be larger than if complemented by a senate-type body. 
The analysis reveals further correlations between size regulation of governance models. In "dual asymmetric" models, the same degree of regulation applies to both bodies. In "dual traditional" models, however, the sample splits almost equally among those where the degree of size regulation is similar for both bodies (Italy, Serbia, UK) and those where different degrees of regulation apply (Austria, North Rhine-Westphalia, Slovenia and Slovakia). Unitary governance models consisting of a single senate-type body are always subject to full-size regulation. Unitary models organised around board-type bodies regulate their size either fully or moderately.

Italy provides a recent example of changes in size regulation. Italian universities have dual governance structures with both board- and senate-types of bodies. Both governing bodies have been reduced in size, and there have been changes in their roles and functions with the 2010 law. The board has been reduced from an average of 20 members to a maximum of 11 members while the senate cannot exceed 35 members. Previously, universities could decide on the size but in practice often maintained large governing bodies. The law is seen as having supported improvements in the quality of management, with a more professional, strategy-oriented university board and reduced duplication through a clarification of the respective functions of both governing bodies.

\section{Composition Rules of Senate-Type Bodies}

Regulations regarding the composition rules for governing bodies of the European universities are characterised by significant heterogeneity. Certain systems are quite explicit about profiles of members for senate-type and/or board-type bodies; others impose certain restrictions while some provide significant freedom to the universities. Following the typology used for size regulation, we distinguish between "full", "moderate" and "no regulation".

While senate-type bodies always include representatives of the academic staff as the largest group, there are different models for other constituencies. On average, the second largest group represented in the senate-type bodies are students (always included), followed by non-academic staff, while very few of the systems include external members in senate-type bodies (Estonia and Ireland, where universities follow unitary governance models, and the UK, where universities may decide on the matter).

Non-academic, i.e. administrative, staff is not represented in the senate-type body in nearly half of the systems of the sample taken up in Table 6. Dual governance structures do not compensate for this; indeed, administrative staff is included in the board-type body only in the case of Slovenia and Slovakia.

The system that imposes the least constraints is the UK where the law does not specify on the membership of the senate. In practice, there are generally academic staff present, students and non-academic staff.

"Moderate" regulation typically applies to student representation in the senate-type body, as in Estonia (minimum $1 / 5$ of student participation) and the Czech Republic (authorised range of $30-50 \%$ students). 
Table 6 Groups represented in senate-type bodies

\begin{tabular}{l|l|l|l|l}
\hline \multicolumn{7}{l}{ Composition of senate-type bodies } & \multicolumn{2}{l}{} \\
\hline System & Academic staff & Non-academic staff & Students & External members \\
\hline AT & $\checkmark$ & $\checkmark$ & $\checkmark$ & $\times$ \\
\hline CZ & $\checkmark$ & $\times$ & $\checkmark$ & $\times$ \\
\hline EE $^{\text {a }}$ & $\checkmark$ & $\times$ & $\checkmark$ & $\checkmark$ \\
\hline FI & $\checkmark$ & $\checkmark$ & $\checkmark$ & $\times$ \\
\hline HR & $\checkmark$ & $\times$ & $\checkmark$ & $\times$ \\
\hline HU & $\checkmark$ & $\checkmark$ & $\checkmark$ & $\times$ \\
\hline IEA & $\checkmark$ & $\checkmark$ & $\checkmark$ & $\checkmark$ \\
\hline IT & $\checkmark$ & $\checkmark$ & $\checkmark$ & $\times$ \\
\hline LU & $\checkmark$ & $\checkmark$ & $\checkmark$ & $\times$ \\
\hline PL & $\checkmark$ & $\checkmark$ & $\checkmark$ & $\times$ \\
\hline RS & $\checkmark$ & $\times$ & $\checkmark$ & $\times$ \\
\hline SI & $\checkmark$ & $\times$ & $\checkmark$ & $\times$ \\
\hline SK & $\checkmark$ & $\times$ & $\checkmark$ & $\times$ \\
\hline UK & $\checkmark$ & $\checkmark$ & $\checkmark$ & $\checkmark$ \\
\hline
\end{tabular}

anitary senate-based governance models

${ }^{\mathrm{b}}$ Not regulated by the law, but present in practice

The rest of the systems clearly specify which member groups need to be included on the senate-type body so that universities only have autonomy in relation to the number of those members. Certain systems, such as Ireland, regulate member composition tightly for each university. However, these parameters differ among Irish universities and are co-created according to the needs and missions of the respective institutions.

\section{Composition Rules of Board-Type Bodies}

External stakeholders form a dominant group, present on all board-type bodies covered by the sample. Apart from the UK and two "free" universities in Flanders, ${ }^{5}$ all systems specify which types of representatives should be included in the board-type bodies, with little leeway provided to individual institutions. Universities may, in some cases, have the capacity to decide on the extent to which they include external members (which sometimes can, in turn, result in the

\footnotetext{
${ }^{5}$ Two of the five "statutory" universities are labelled as "free" universities: KU Leuven and Vrije Universiteit Brussel. With respect to autonomy, the free universities only differ from the other universities in that they have greater freedom to decide on the composition and size of their governing boards. The differences between the types of universities are mainly due to historical factors linked to their foundation and their stakeholders.
} 
exclusion of other groups). An example of this can be found in the German state of North Rhine-Westphalia where the law specifies that universities need to have at least $50 \%$ of external members while the maximum can be as high as $100 \%$. Students, academic staff and non-academic staff may or may not be included. In some systems, the board-type bodies may include external members only, which can be observed in Austria, the Czech Republic, Netherlands (in the case of the "supervisory" body) and Slovakia. On the opposite end of the spectrum, external members remain a small minority in the university boards of other countries (less than $1 / 5$ in Serbia for instance).

Unitary governance models structured around board-type bodies tend to include all four groups, except for Iceland and Sweden, where regulations do not specifically stipulate the inclusion of non-academic staff in the board (Sweden) or include them in the advisory senate-type body (Iceland).

Aside from the fully external boards listed above, all board-type bodies include at least three out of the four constituencies (Table 7). External members are always present and so is academic staff. Non-academic staff and students are found slightly less frequently (roughly 2/3 of the cases where a board-type body exists).

Table 7 Composition of board-types at European universities

\begin{tabular}{l|l|l|l|l}
\hline Composition of board-type bodies & \multicolumn{5}{l}{} \\
\hline System & Academic staff & Non-academic staff & Students & External members \\
\hline AT & $\times$ & $\times$ & $\times$ & $\checkmark$ \\
\hline BE-FL & $\checkmark$ & $\checkmark$ & $\checkmark$ & $\checkmark$ \\
\hline CZ & $\times$ & $\times$ & $\times$ & $\checkmark$ \\
\hline DE-NRW & $\checkmark$ & $\checkmark$ & $\times$ & $\checkmark$ \\
\hline DK $^{\text {a }}$ & $\checkmark$ & $\checkmark$ & $\checkmark$ & $\checkmark$ \\
\hline FI & $\checkmark$ & $\checkmark$ & $\checkmark$ & $\checkmark$ \\
\hline HR & $\checkmark$ & $\times$ & $\checkmark$ & $\checkmark$ \\
\hline HU & $\checkmark$ & $\checkmark$ & $\times$ & $\checkmark$ \\
\hline IS & $\checkmark$ & $\times$ & $\checkmark$ & $\checkmark$ \\
\hline IT & $\checkmark$ & $\times$ & $\checkmark$ & $\checkmark$ \\
\hline LU $^{\mathrm{a}}$ & $\checkmark$ & $\times$ & $\checkmark$ & $\checkmark$ \\
\hline NL & $\checkmark$ & $\checkmark$ & $\times$ & $\checkmark$ \\
\hline NO $^{\mathrm{b}}$ & $\checkmark$ & $\checkmark$ & $\checkmark$ & $\checkmark$ \\
\hline PT $^{\mathrm{a}}$ & $\checkmark$ & $\checkmark$ & $\checkmark$ & $\checkmark$ \\
\hline RS $_{S E^{\mathrm{a}}}$ & $\checkmark$ & $\times$ & $\checkmark$ & $\checkmark$ \\
\hline SI & $\checkmark$ & $\times$ & $\checkmark$ & $\checkmark$ \\
\hline SK & $\times$ & $\checkmark$ & $\checkmark$ & $\checkmark$ \\
\hline $\mathrm{UK}^{\mathrm{c}}$ & $\checkmark$ & $\times$ & $\times$ & $\checkmark$ \\
\hline
\end{tabular}

anitary board-based governance models

bBoth "board-type" bodies combined (executive board and supervisory board)

${ }^{\mathrm{c}}$ Not regulated by the law, but present in practice 
External members are excluded from the university governance in Poland which follows a unitary, senate-based structure. Non-academic staff is fully excluded from university governance structures in the following systems: Czech Republic, Croatia, Slovakia and Serbia, where university governance is "dual traditional"; Sweden and Iceland, with the caveats made above; and Estonia (in the unitary, senate-based model used in four out of six universities).

Students are fully excluded from central governance structures in Dutch universities. Following tensions in 2016, the regulatory framework evolved in 2017, resulting in increased student representation in governing bodies at department/ faculty level.

In terms of member participation in the decision-making process, it is important to point out that not all members of the governing bodies have voting rights. It is usually the case that the rectors sit on governing bodies but have no voting rights (as in Croatia), or the head of administration and secretary generals (as in Luxembourg for example), or government officials (as in Flanders). In four systems, certain members on board-type bodies have no right to vote, while in 5 systems there are certain member on the senate-type bodies that cannot vote.

\section{Profiles of External Members}

The inclusion of external members in university governance is an important element for accountability purposes, outreach to society and enhanced linkages with other parts of the economy. It plays a role in the ability of universities to develop a strategic profile in an increasingly competitive environment. The Autonomy Scorecard details modes of selection of external members, revealing that the involvement of public authorities in this process remains significant in many higher education systems.

On average, external members account for around 50\% of board-type bodies membership (Table 8). Few systems allow universities to fully decide on the type of external members to include - industry/business representatives, NGO representatives, alumni, local/national authorities, academic staff from other universities or representatives of art \& culture. The majority either restrict the universities' ability to determine profiles (6 systems) or give full control to public authorities (9 systems). Some systems that regulate external member participation more closely also sometimes stipulate the requirements/competencies that these members need to possess to qualify for inclusion to the governing bodies. Some of these requirements include previous experience with management, specific knowledge, recognised merit, etc. The law prescribes certain competencies requirements for the external members, although to different extents, in Denmark, Croatia, Hungary, Iceland, Italy, Ireland, Luxembourg and Serbia.

The most frequently represented group among external members comes from industry and businesses. Out of 19 systems that have board-type bodies, 17 of them include industry/business representatives. In practice, the share is even higher as 
Table 8 External member distribution in board-types bodies

\begin{tabular}{l|l|l|l}
\hline System & Less than 50\% external members & $50 \%$ and above & $100 \%$ \\
\hline AT & & & $\checkmark$ \\
\hline BE-FL & $\checkmark$ & & \\
\hline CZ & & $\checkmark$ & $\checkmark$ \\
\hline DE-NRW & & $\checkmark$ & \\
\hline DK & & $\checkmark$ & \\
\hline FI & $\checkmark$ & $\checkmark$ & \\
\hline HR & & & \\
\hline HU & & & \\
\hline IS & $\checkmark$ & $\checkmark$ & \\
\hline IT & $\checkmark$ & & $\checkmark$ \\
\hline NU & & & \\
\hline NO & & & \\
\hline PT & $\checkmark$ & & \\
\hline RS & $\checkmark$ & $\checkmark$ & \\
\hline SE & & & \\
\hline SI & $\checkmark$ & & \\
\hline SK & & $\checkmark$ & \\
\hline UK & & & \\
\hline
\end{tabular}

Denmark and UK do not specify the profiles of external members in university governance, but institutions include them as well. However, at system level, industry and business representatives may not necessarily be the largest group of external members on the governing body. For instance, in Italy, it is more likely to have more government officials as external members on the Board than industry/ business representatives.

National and local authorities are the second most represented group in the boards. This might not be a legal requirement but rather a tradition to include a representative of the Ministry of Education (Czech Republic). In Luxembourg, a "government commissioner" is present on the board, without voting rights. Some systems specify what type of public authority is to be present in the governing body (local, regional, national authorities). This is the case, for instance, with Ireland where it is mandatory for some universities to have mayors of the city present in the senate-type body.

The third most represented group of external members includes the academic staff from other universities. There are 14 systems that include this group, among which Sweden, Norway and Luxembourg. Alumni are least often represented but still participate in university governance in 10 systems, including Sweden, Finland and Hungary. 


\section{Governance Models and Inclusiveness}

The following chart shows a simplified assessment of the "inclusiveness" of university governance structures across Europe. It does so by exposing the number of different groups included in each governing body, differentiating between academic staff, non-academic staff, students and external members. Unitary systems are given a zero score for the absent governing body. This allows comparing both unitary and dual governance structures simultaneously. A limitation is, nevertheless, the inability of the chart to point to overlaps between governing bodies and full exclusion of certain groups from a given governance structure (as detailed above) (Fig. 1).

The chart shows that unitary systems are on average rather inclusive, with a half including 3 groups and a half including all four groups. Given the small number of unitary senate-based models in the sample, it is not possible to draw conclusions on the relative merits of senate- or board-based unitary models in relation to inclusiveness. Two unitary senate-based models exclude one group-either external members or non-academic staff; three unitary board-based models exclude one group - either students or non-academic staff.

Dual governance models generally have at least three groups represented in each body. However, Eastern European universities are more likely to have more imbalance between the two bodies, and more homogeneous senates (no more than

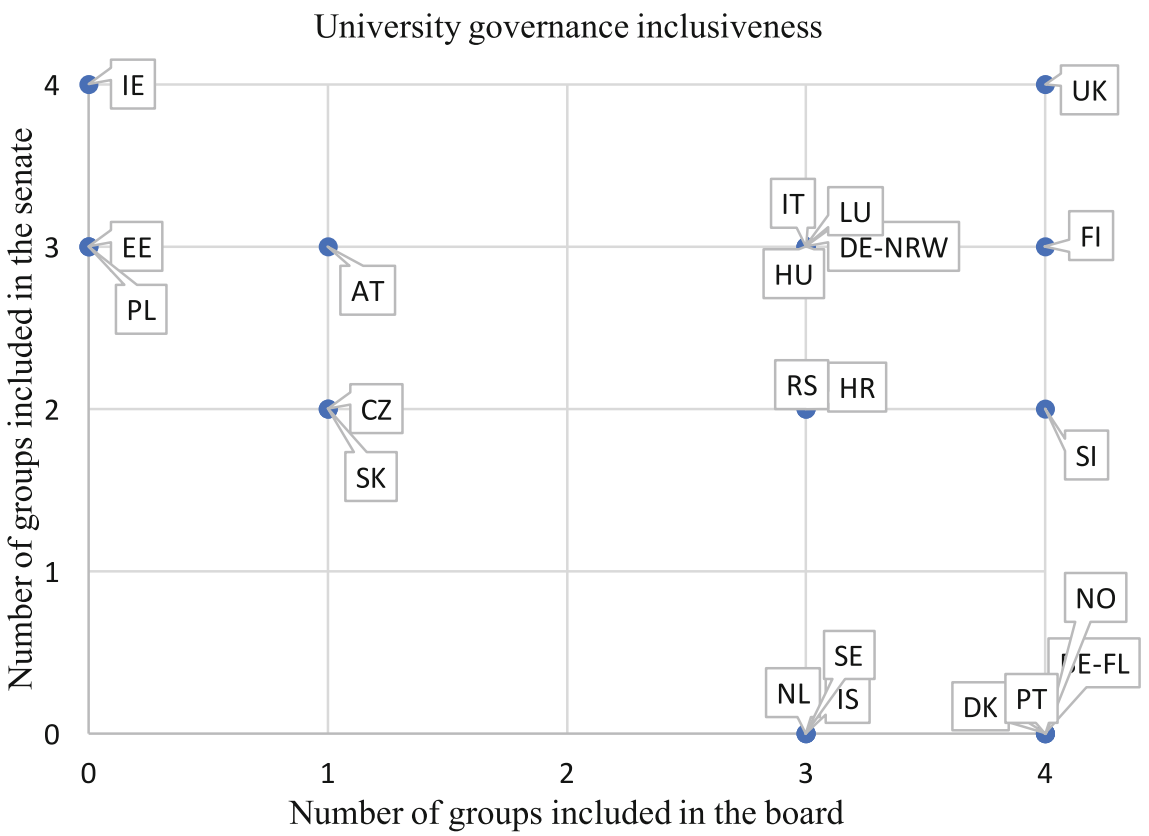

Fig. 1 University governance inclusiveness 
two groups represented: academic staff and students). The Czech Republic and Slovakia present special characteristics with a senate in line with the above and a fully external board. Austria also resorts to fully external university boards.

Finally, significant inclusiveness/diversity in governance structures may be achieved through comparatively lower levels of regulation, as in the UK (data for the UK represents common practice as universities enjoy high levels of autonomy in this area).

\section{Governance Trends}

It can be argued that governing modes across European university systems are evolving in the direction of granting board-type bodies more power through different avenues. There are several governance changes and novelties that illustrate this phenomenon. The Estonian system saw two major governance changes in 2012 and 2014 when two out of six universities obtained their own regulatory framework, separate from the general Universities Act. The two universities now have their own acts which they used to form board-type bodies that now not only co-exist with the senate-type bodies but are granted more power share. This means that for these two universities the governance model has changed from unitary to dual-asymmetric model. In the case of the Czech Republic, the Board of Trustees, which previously had no formal powers, now has the competence to approve the university budget, owing to the recent act amendment. In Norway, there have been debates around the modalities of rector selection, with the perspective to entrust boards exclusively with the rector appointment. Norwegian universities are currently able to choose between two models of rector election (via board or via electoral body).

Further governance changes relate to alterations in number and composition of certain governing bodies. In Italy, the number of governing body members has been capped and requirements of certain members have become more regulated. In Austria, a change in composition saw the reduction of what used to be the majority group-full-time professors - to foster the representation of different groups. Changes concern external member regulation as well. In Denmark, the universities now must set up a committee which would nominate external members to the board and in Estonia, external members are to be appointed by the external authority. Sweden is another system that announced a new selection process for the external members.

There is particular evidence of developments in relation to gender equality. In 2014, Austria has made it a legal provision that there be at least $50 \%$ of female participation in the governing bodies (rectorate, senate and council). This is part of a larger framework related to the promotion of gender equality in public decision-making bodies in Austria. North Rhine-Westphalia introduced a similar regulation whereby $40 \%$ of the council members must be women. 
Multiple governance reforms have affected universities' organisational autonomy. Out of 22 systems covered in this study, 12 have undergone (significant) governance changes in the last five years.

The need to increase the efficiency, save resources and minimise the administrative burden seems to have been one of the drivers for governance changes, including the growing number of mergers in several systems.

In several countries, the legal status of universities has changed. Due to the diversity of national legislative frameworks, individual organisational forms are difficult to compare. However, the new status usually offers greater freedom from the state and, in most cases, goes hand in hand with increased participation of external members in the university governing bodies.

Different governance models continue to co-exist, sometimes within the same systems. More systems carry out policy experimentations in the field of organisational autonomy, allowing selected universities to gain greater freedom in re-designing their governance (as in Estonia), testing new appointment models for executive heads (in Norway), or granting more institutions recently developed legal statuses (in Portugal and Sweden).

Recent changes in this field include developments in Estonia, Italy, or Lithuania. In these countries, reflection on the roles and responsibilities of governing bodies brought about the introduction or re-design of board-type bodies in all or some universities of the system. This usually was combined with a more noticeable presence and role of external members in these bodies.

In a majority of European countries, external members participate now in the most important decisions in university governance. In some cases, they have now gained fully equal rights in the board with internal members (as in France). Selection and nomination processes have also been revised to the advantage of the university (Italy, Lithuania and Sweden). The "type" of external members involved in university governing bodies remains an issue in some systems. When they come from public authorities, their involvement may be seen as a way for the state to gain greater influence over internal decision-making processes, thus reducing institutional autonomy, or conversely as a practical way to clear potential subsequent hurdles.

In most Northern European countries, universities can freely select their external members, although in some of these countries, an external authority formally appoints external members who were put forward by the university. In a majority of systems, the government continues to partly or completely control the appointment of external members.

The analysis of the updated Scorecard also shows, importantly, that there is not a single linear progress curve with systems inexorably allowing more autonomy to universities. While there is noticeable progress recorded in the field of organisational autonomy, there are also a series of setbacks, with different kinds of meaning for higher education in general. Although this is an isolated case, developments in Hungary show that there can be direct interventions of the state aimed at re-asserting more control over university activities. In other cases, such as Ireland, it is the continued constrained financial conditions that consolidate a less autonomous 
environment for universities over the medium term. Governance is a key factor for universities to perform efficiently and carry out their missions. This includes both a productive relationship with public authorities characterised by an enabling regulatory framework and adequate internal governance models. For the latter, it is essential to achieve the right balance between the necessity to include a broad and diverse university community and the development of structures and processes that support efficient decision-making and, therefore, flexible and responsive management. The overview provided in this paper shows that there is a certain convergence across Europe, despite the existing diversity, to attain this objective.

\section{Reference}

Pruvot, E. B., \& Estermann, T. (2017). University Autonomy in Europe III: The Scorecard 2017. Brussels: EUA.

Open Access This chapter is licensed under the terms of the Creative Commons Attribution 4.0 International License (http://creativecommons.org/licenses/by/4.0/), which permits use, sharing, adaptation, distribution and reproduction in any medium or format, as long as you give appropriate credit to the original author(s) and the source, provide a link to the Creative Commons license and indicate if changes were made.

The images or other third party material in this chapter are included in the chapter's Creative Commons license, unless indicated otherwise in a credit line to the material. If material is not included in the chapter's Creative Commons license and your intended use is not permitted by statutory regulation or exceeds the permitted use, you will need to obtain permission directly from the copyright holder.

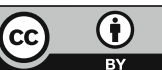

